\title{
Characterization of telomeric repeat-containing RNA (TERRA) localization and protein interactions in primordial germ cells of the mouse
}

\author{
Miguel A. Brieño-Enríquez*, Steffanie L. Moak, Anyul Abud-Flores \\ and Paula E. Cohen*
}

Department of Biomedical Sciences and the Cornell Center for Reproductive Genomics, Cornell University, Ithaca, New York, USA

\begin{abstract}
*Correspondence: Department of Biomedical Sciences and the Cornell Center for Reproductive Genomics, Cornell University, Veterinary Research Tower T3014, Tower Road, Ithaca, NY 14853, USA; E-mail: paula.cohen@cornell.edu and brienoenriquezma@upmc.edu
\end{abstract}

\begin{abstract}
† Grant support: The research reported in this publication was supported by the Eunice Kennedy Shriver National Institute of Child Health and Human Development of the National Institutes of Health under Award Number P50HD076210 to PEC, and through a seed grant to MAB-E from The Cornell Center for Reproductive Genomics. Salary support for MAB-E was provided through a training grant from the Empire State Stem Cell Fund through New York State Department of Health Contract \# C30293GG (PI: Alexander Nikitin), and through funding from the Eunice Kennedy Shriver National Institute of Child Health \& Human Development of the National Institutes of Health under Award Number K99HD090289 to MAB-E Imaging data was acquired through the Cornell University Biotechnology Resource Center, with NSF funding \#1428922 for the shared Zeiss Elyra Microscope. NIH SIG 1S10 0D017992-01 grant support the Orbitrap Fusion mass spectrometer. The funders had no role in study design, data collection and analysis, decision to publish, or preparation of the manuscript. Edited by Dr. Jeremy P. Wang, MD, PhD, University of Pennsylvania
\end{abstract}

Received 26 July 2018; Revised 10 September 2018; Accepted 9 November 2018

\begin{abstract}
Telomeres are dynamic nucleoprotein structures capping the physical ends of linear eukaryotic chromosomes. They consist of telomeric DNA repeats (TTAGGG), the shelterin protein complex, and telomeric repeat-containing RNA (TERRA). Proposed TERRA functions are wide ranging and include telomere maintenance, telomerase inhibition, genomic stability, and alternative lengthening of telomere. However, the presence and role of TERRA in primordial germ cells (PGCs), the embryonic precursors of germ cells, is unknown. Using RNA-fluorescence in situ hybridization, we identify TERRA transcripts in female PGCs at 11.5, 12.5, and 13.5 days postcoitum. In male PGCs, the earliest detection TERRA was at $12.5 \mathrm{dpc}$ where we observed cells with either zero or one TERRA focus. Using qRT-PCR, we evaluated chromosome-specific TERRA expression. Female PGCs showed TERRA expression at $11.5 \mathrm{dpc}$ from eight different chromosome subtelomeric regions (chromosomes 1, 2, 7, 9, 11, 13, 17, and 18) while in male PGCs, TERRA expression was confined to the chromosome 17. Most TERRA transcription in $13.5 \mathrm{dpc}$ male PGCs arose from chromosomes 2 and 6. TERRA interacting proteins were evaluated using identification of direct RNA interacting proteins (iDRiP), which identified 48 in female and 26 in male protein interactors from PGCs at $13.5 \mathrm{dpc}$. We validated two different proteins: the splicing factor, proline- and glutamine-rich (SFPO) in PGCs and non-POU domain-containing octamer-binding protein (NONO)
\end{abstract}


in somatic cells. Taken together, our data indicate that TERRA expression and interactome during PGC development are regulated in a dynamic fashion that is dependent on gestational age and sex.

\section{Summary Sentence}

TERRA transcription and interacting proteins during PGC development are regulated in a dynamic fashion that is dependent on gestational age and sex.

Key words: TERRA, primordial germ cells, long non-coding RNA, telomeres.

\section{Introduction}

Telomeres are dynamic nucleoprotein structures capping the physical ends of linear eukaryotic chromosomes. They protect the chromosome ends from degradation and erroneous recombination events and, as such, are essential for ensuring genome stability [1]. They also play a very important role in the movement, localization, and anchoring of the chromosomes to the nuclear membrane [2]. In germ cells, telomeres are involved in the pairing and synapsis of the homologous chromosomes during meiotic prophase. Alterations in telomere length of structure compromise the gamete development, increasing the risk of aneuploidy, germ cell apoptosis, and subfertility [3-6].

Telomeres consist of DNA, proteins, and RNA. Telomeric DNA consists of double-strand DNA repeats (TTAGGG) that extend 9$15 \mathrm{~kb}$ in length in humans but can be as long as $100 \mathrm{~kb}$ in rodents [6-8]. The protein component of the telomere is comprised of the shelterin complex, consisting of TRF1, TRF2, RAP1, TIN2, TPP1, and POT1 [9]. The shelterin complex plays numerous roles in telomere stabilization, including suppression of the DNA damage response and the regulation of telomerase activity [10]. The telomeric RNA component is a long non-coding RNA $[6,11-14]$ and known as TERRA (telomeric repeat-containing RNA). TERRA transcripts are comprised of UUAGGG repeats that are transcribed by RNA polymerase II, initiating from the subtelomeric regions of the telomeres and proceeding toward the chromosome ends [9]. TERRA transcription in human cells is regulated by promoters localized at all subtelomeric regions, and by methylation on the $\mathrm{CpG}$ islands of these promoters [15]. By contrast, in mice only one promoter has been described on chromosome 18 and its regulation does not appear to be dependent on methylation [16]. TERRA expression levels and localization are cell cycle dependent, being high during the G1-S transition, peaking at early $S$ phase and declining as cells transition to $\mathrm{G} 2$ and $\mathrm{M}$ phase [15]. TERRA was initially described to be associated exclusively with the ends of linear eukaryotic DNA, but recently studies have indicated that it also associates with other regions of the genome such as the pseudoautosomal regions of sex chromosomes and within internal chromosomal regions and within genes, where it favored introns [17].

Several TERRA functions have been described, including telomere maintenance, telomerase inhibition, telomeric heterochromatin formation, genomic stability, an alternative lengthening mechanism for telomeres [17-19], and regulation of telomerase [17, 20]. More recently, TERRA has been implicated in the protection of telomere stability, in which TERRA competes with ATRX to bind to DNA [17], and in the regulation of X chromosome pairing during female $\mathrm{X}$ chromosome inactivation, where TERRA creates a hub to guide $\mathrm{X}$ inactivation center homology searching [21].

TERRA localizes to the telomeres of mammalian germ cells (oocytes and spermatocytes) during all stages of meiotic prophase I, where it appears to be regulated in a sex-specific manner $[6,22]$. However, the role of TERRA during these stages remains unclear.
Preliminary data suggest that TERRA transcription initiates in the primordial germ cell (PGC) stage [23]. Primordial germ cells are the embryonic precursors of the germ cell lineage that will form the oocytes and sperm required for sexual reproduction [24, 25]. In mice, PGCs first become identifiable as a cluster of approximately 40 cells around embryonic day 6.25 days postcoitum $(\mathrm{dpc})[24,26]$, and reaching their maximal numbers by approximately $13.5 \mathrm{dpc}$ through continued migration and proliferation [27]. Just after the gonad colonization PGCs go a process where they erasure the methylation marks, reaching the lower levels of methylation at approximately $13.5 \mathrm{dpc}$. In the female embryo, at $13.5 \mathrm{dpc}$ PGCs then enter prophase I of meiosis and arrest at diplotene by around the time of birth. Meanwhile, male PGCs at this gestational age undergo mitotic arrest in the $G_{0} / G_{1}$ phase and stay quiescent for the remainder of the embryonic period, only initiating meiosis after birth [24]. We hypothesized that the transcription and localization of TERRA within PGCs will increase inversely with the drop in DNA methylation that occurs during this period of time.

In the current study, we have investigated the localization, transcription, and protein interactions of TERRA in male and female PGCs just after sex determination, and prior to the time that female germ cells enter meiosis and male germ cells become quiescent. Our results demonstrate that TERRA expression, localization, and interactome in PGCs are sexually dimorphic and dependent on developmental age, suggesting that TERRA regulation may be an important component of the sex-specific development of the mammalian germ line.

\section{Materials and methods}

\section{Mouse handling and care}

All mouse studies were conducted with the prior approval of the Cornell Institutional Animal Care and Use Committee. A total of six to eight weeks old wild-type $\mathrm{C} 57 \mathrm{~B} 1 / 6 \mathrm{~J}$ mice were mated and checked for vaginal plugs the next morning. Female mice with plugs were moved into a separate cage, and were considered to be at $0.5 \mathrm{dpc}$. At $11.5,12.5$, and $13.5 \mathrm{dpc}$, the mothers were sacrificed to recover gonads from fetuses for the isolation of PGCs.

\section{Extraction of primordial germ cells}

Primordial germ cells were purified by magnetic cell sorting of gonads from 11.5, 12.5, and $13.5 \mathrm{dpc}$ male and female embryos following a published protocol with some modifications [28, 29]. Briefly, the gonads from 11.5, 12.5, and $13.5 \mathrm{dpc}$ embryos were dissected under a stereomicroscopy in EmbryoMax M2 Medium (Merck-Millipore). Gonads at 12.5 and 13.5 dpc were classified according to the anatomical characteristics. For $11.5 \mathrm{dpc}$, gonads dissected and sexed by PCR following the method described previously [30]. Testis and ovaries were disaggregated in $0.25 \%$ trypsin-EDTA containing $20 \mu \mathrm{g} / \mathrm{ml}$ 
DNase (Sigma-Aldrich, St. Louis, MO) at RT. The enzymatic reaction was stopped by adding M2 medium with 10\% FCS (Gibco, Thermo Fisher, Waltham, MA). The cells were centrifuged at 3220 rcf for 2 min and washed twice with $500 \mu 1$ of M2 medium containing $10 \% \mathrm{FCS}$ and $20 \mu \mathrm{g} / \mathrm{ml}$ DNase. The cell pellet was resuspended in $400 \mu \mathrm{l}$ of M2 medium, mixed with $30 \mu \mathrm{l}$ anti-SSEA-1 (CD15) MicroBeads (Miltenyi Biotech, Bergisch Gladbach, Germany), and incubated for $45 \mathrm{~min}$ at $4{ }^{\circ} \mathrm{C}$. Primordial germ cells were isolated from somatic cells with a miniMACs column following the manufacturer's instructions and counted (Miltenyi Biotech). The purity of PGCs was verified by counting cells that stained positive for alkaline phosphatase with the naphtol AS-MX/FAST-RED procedure (Sigma-Aldrich). In all cases the purity of the PGCs was evaluated from cell counts in four different fields of the microscope until a total number of 100 cells were recorded. The purity of PGCs varies according to gestational age: at $11.5 \mathrm{dpc}$, cell suspensions showed a purity/enrichment of $80-85 \%$, at $12.5 \mathrm{dpc}$ the purity/enrichment of PGCs ranged from 85 to $89 \%$, and at $13.5 \mathrm{dpc}$ PGC there was a recorded $90-95 \%$ purity/enrichment. Typical yield of PGCs per embryo varies by gestational age. At $11.5 \mathrm{dpc}$, the total isolated PGCs was approximately 800 , at $12.5 \mathrm{dpc}$ there were approximately 4000 PGCs isolated per embryo, and approximately 10000 PGCs per embryo at $13.5 \mathrm{dpc}$. The somatic cells (Soma) were separated in the MS column were also collected for analysis. We evaluated the reactivity of the SSEA-1 antibody on tissue sections from female and male gonads (Supplementary Figure S1).

\section{Primordial germ cells and somatic cell spreading}

After extraction, $20 \mu \mathrm{l}$ of the cell suspension was placed on poly-Llysine slides that were previously cleaned with RNaseZap (Thermo Fisher). Cells were permeabilized by incubation for $10 \mathrm{~min}$ in CSK buffer $\left(100 \mathrm{mM} \mathrm{NaCl}, 300 \mathrm{mM}\right.$ sucrose, $3 \mathrm{mM} \mathrm{MgCl}_{2}$, $10 \mathrm{mM}$ PIPES (Sigma-Aldrich), 0.5\% Triton X-100 (Fisher Scientific, Pittsburgh, PA), and $10 \mathrm{mM}$ ribonucleoside-vanadyl complex (New England Biolabs, Ipswich, MA)) [31]. Cells were fixed in 4\% paraformaldehyde (Electron Microscopy Sciences, Hatfield, PA) for $10 \mathrm{~min}$ and then washed in $70 \%$ ethanol. Slides were stored at $-80^{\circ} \mathrm{C}$ until use.

\section{Immunofluorescence}

Immunofluorescence (IF) was performed as previously described with modifications [31]. Slides were blocked $10 \mathrm{~min}$ with PTBG (1x PBS, $0.1 \%$ Tween- $20,0.2 \%$ BSA, $0.2 \%$ gelatin) and then incubated overnight at $4{ }^{\circ} \mathrm{C}$ with mouse anti-TERT (dilution 1:100 from Rockland antibodies \#600-401-252S), anti-NONO (dilution 1:100 from Proteintech \#11058), anti-SFPQ (dilution 1:100 from Proteintech \#15585), anti-SSEA-1 (dilution 1:100 from Abcam \#ab16285), and anti-VASA (DDX4) (dilution 1:200 from Abcam \#ab13840) in PTBG. Slides were washed three times for $5 \mathrm{~min}$ in PBST $(0.1 \%$ Tween-20 in $1 \mathrm{x}$ PBS) before incubation at $37^{\circ} \mathrm{C}$ for $40 \mathrm{~min}$ with the following secondary antibodies: Alexa Fluor 488-AffiniPure F(ab')2 Fragment goat anti-mouse $\operatorname{IgG}(\mathrm{H}+\mathrm{L})$, Alexa Fluor 488-AffiniPure $\mathrm{F}\left(\mathrm{ab}^{\prime}\right) 2$ Fragment goat anti-rabibit $\operatorname{IgG}(\mathrm{H}+\mathrm{L})$, and Alexa Fluor 594-AffiniPure F(ab')2 Fragment goat anti-rabbit IgG $(\mathrm{H}+\mathrm{L})$, all of them from Jackson Immunoresearch (West Grove, PA). Secondary antibodies were incubated at concentrations of 1:1000 in PTBG at $37^{\circ} \mathrm{C}$ for $60 \mathrm{~min}$. Slides were washed three times in PBST, fixed with $4 \%$ paraformaldehyde in $1 \mathrm{x}$ PBS for $10 \mathrm{~min}(\mathrm{pH} 7)$, and rinsed with $1 \mathrm{x}$ PBS. At the end of the IF procedure, RNA-fluorescence in situ hybridization (RNA-FISH) was performed.

\section{RNA-fluorescence in situ hybridization}

TERRA focus detection was performed by RNA-FISH [31, 32]. RNA-FISH was performed immediately after IF. Briefly, after dehydration through an ice-cold graded ethanol series $(70 \%, 80 \%, 90 \%$, and $100 \%$, during $5 \mathrm{~min}$ each), cells were hybridized overnight at $37^{\circ} \mathrm{C}$ with a $25-\mathrm{nM}$ (CCCTAA $)^{3}$ oligonucleotide probe conjugated with Cy3 (Integrated DNA Technologies IDT, Coralville, IO) in hybridization buffer (10\% of 20x SSC (Sigma-Aldrich), $20 \% 10$ $\mathrm{mg} / \mathrm{ml} \mathrm{BSA} \mathrm{(Sigma-Aldrich),} 20 \%$ of $50 \%$ dextran sulfate (Fisher Scientific), and $5 \%$ deionized formamide (Fisher Scientific)) (Probe specificity was tested in mouse embryonic fibroblasts, MEF, not shown). Next, slides were washed with $50 \%$ formamide/1xSSC during $5 \mathrm{~min}$ followed by two washes of $2 \mathrm{x} \mathrm{SSC}$ at $39^{\circ} \mathrm{C}$. Finally, cell nuclei were counterstained with 4,6-diamidino-2-phenylindole (DAPI) diluted in Vectashield (Vector Laboratories, Burlingame, CA). For each sample, a negative control was included, consisting of slides treated 10 min with RNAse A (Sigma-Aldrich) at a concentration of $100 \mu \mathrm{g} / \mathrm{ml}$ prior to RNA-FISH performance. Foci were counted as signals that appeared as discrete dots or signals within the cell. At least 75 cells were counted per each PGC pool and 50 for each somatic cell pool.

\section{Immunohistochemistry}

Immunohistochemistry was performed on paraffin-embedded sections from $13.5 \mathrm{dpc}$ ovaries and testis. Slides were deparaffinized and rehydrated with three washes of Safeclear (Fisher Scientific) for $5 \mathrm{~min}$ each, followed by three washes of each concentration in a graded series of ethanol $(100 \%, 95 \%, 80 \%, 70 \%)$. After rinsing the slides twice for $5 \mathrm{~min}$ in distilled water, the slides were incubated in sodium citrate $\mathrm{pH} 6.0$ during $40 \mathrm{~min}$ at $95^{\circ} \mathrm{C}$. Permeabilization was performed in $0.2 \%$ of Triton-X 100 in PBS for $30 \mathrm{~min}$. Section were blocked for $4 \mathrm{~h}$ in blocking solution (2.52 $\mathrm{mg} / \mathrm{ml}$ glycine, $10 \%$ goat serum, $3 \%$ BSA in PBS-T) and then incubated with primary antibody overnight at RT. After two washes with PBST, the slides were incubated with secondary antibodies for $2 \mathrm{~h}$ at RT. The slides were rinsed in PBST; cell nuclei were counterstained with DAPI and mounted in Vectashield (Vector Laboratories).

\section{Imaging}

Imaging of PGCs and somatic cells was performed using ELYRA 3DStructured Illumination Super resolution Microscopy (3D-SIM) from Carl Zeiss with ZEN Black software (Carl Zeiss AG, Oberkochen, Germany). Images are shown as maximum intensity projections of $\mathrm{z}-$ stack images using 3D-SIM. To reconstruct high-resolution images, raw images were computationally processed by ZEN Black. Channel alignment was used to correct for chromatic shift. The brightness and contrast of images were adjusted using ImageJ (National Institutes of Health). Image acquisition of the tissue sections was performed using a Zeiss Imager Z1 microscope under $\times 20, \times 40$, or $\times 63$ magnifying objectives at RT. Images were processed using ZEN 2 (Carl Zeiss $A G)$.

\section{RNA isolation and reverse transcription}

Total RNA from each gestational age $(11.5,12.5$, and $13.5 \mathrm{dpc}$ for both male and female gonads) was extracted using TRIzol (Invitrogen Co, Carlsbad, CA). Total RNA was resuspended in 40 $\mu \mathrm{l}$ of RNase-free water. RNA concentration was then determined spectrophotometrically using a NanoDrop 2000 (Thermo Fisher). $1.5 \mu \mathrm{g}$ of total RNA was reverse transcribed using the Superscript III 
First-Strand Synthesis System (Invitrogen Co) with TERRA reverse primer or $1.65 \mu \mathrm{M}$ random hexamers/1.25 $\mu \mathrm{M}$ Oligo(dt) for the housekeeping gene (Supplementary Table S1). Complementary DNA was kept at $-20^{\circ} \mathrm{C}$ until used in qRT-PCR.

\section{Quantitative RT-PCR analysis}

Quantitative reverse transcriptase PCR amplification (qRT-PCR) and analysis was performed following the protocol previously described by Feretzaki and Lingner [33]. Primers were designed to amplify the subtelomeric region of different chromosomes using the sequences previously published by Lopez de Silanes et al. [16] (Supplementary Table S1). (Subtelomeric regions with active transcription of functional genes were not included.) Primers were first tested to amplify the desired specific subtelomeric region using conventional PCR, and we selected the ones that showed the specific product. The selected primers were subjected to postamplification melting curves analyses to ensure the absence of primer dimer artifacts and unspecific amplifications as was described by Feretzaski and Ligner [33]. Lowest concentration of RNA was tested to establish the reliably measured Ct. Gene expression was normalized to succinate dehydrogenase complex flavoprotein subunit A (SDHA) expression. Previously, van den Bergen et al. showed that SHDA is a very stable gene in both male and female PGCs from 11.5 to $15.5 \mathrm{dpc}$ [34]. We performed several standardization assays, and the expression of SDHA did not show changes along the gestational age or sex. Each reaction mixture consisted of $1 \mu \mathrm{l}$ of cDNA, $0.5 \mu \mathrm{l}$ of forward primer $(0.2 \mu \mathrm{M}), 0.5 \mu \mathrm{l}$ of reverse primer $(0.2 \mu \mathrm{M}), 10 \mu \mathrm{l}$ of Roche FastStart SYBR Green Master (Sigma-Aldrich), and $7 \mu \mathrm{l}$ of nuclease-free water. Quantitative RT-PCR amplification reaction was performed with specific primers (Supplementary Table S1). PCR conditions were the same as those used by Feretzaki and Lingner [33]: $30 \mathrm{~s}$ at $95^{\circ} \mathrm{C}$, followed by 40 cycles at $95^{\circ} \mathrm{C}$ for $1 \mathrm{~s}$ and $60^{\circ} \mathrm{C}$ for $60 \mathrm{~s}$. After PCR, melting curve analyses were performed to verify specificity and identity of the PCR products. All data were analyzed with the CFXmanager Bio-Rad (Bio-Rad Laboratories). All analyzed genes were performed in triplicate for each one of the three biological samples of the three different developmental ages $(11.5,12.5$, and $13.5 \mathrm{dpc})$ and both sexes (female and male). Quantitative RT-PCR data for TERRA quantification are analyzed using the relative quantification method [35]. This method feeds the Ct values obtained from the qRT-PCR experiment into a series of subtractions to calculate the relative gene expression of the gene of interest (TERRA) normalized against a reference gene (SDHA) in different conditions as was described previously $[17,21,33]$.

\section{Identification of direct RNA interacting proteins}

Proteins that directly interact with TERRA were identified through method called identification of direct RNA interacting proteins (iDRiP), following a published protocol with some adaptations [36]. The original iDRiP method utilized large numbers of cultured somatic cells (around 30 million). In the current study, we adapted the conditions to reduce the input of cells around 10-fold and to use primary PGCs from $13.5 \mathrm{dpc}$ male and female gonads, along with gonadal somatic cells as controls. Probe specificity was tested in MEFs, and the results obtained were comparable to those previously published using a variety of methods [17, 37, 38]. After cell isolation, cells were rinsed with cold PBS three times and then plated in a petri dish for $30 \mathrm{~min}$ at $37^{\circ} \mathrm{C} 5 \% \mathrm{CO}_{2}$. Excess $\mathrm{PBS}$ was removed and the cells were irradiated with UV light at $200 \mathrm{~mJ} / \mathrm{cm}^{2}$ energy (Spectrolinker XL, UV crosslinker, Spectronics Corporation,
Westbury, NY). The cells were transferred to an eppendorf tube and spun down at $1258 \mathrm{rcf}$ for $5 \mathrm{~min}$ at $4^{\circ} \mathrm{C}$. The pellet was resuspended in $300 \mu \mathrm{l}$ cold cytoskeleton buffer (CSKT) $(0.5 \%$ Triton X-100, $0.5 \%$ PIPES, $100 \mathrm{mM} \mathrm{NaCl}, 3 \mathrm{mM} \mathrm{MgCl}, 0.3 \mathrm{M}$ sucrose, and $1 \mathrm{mM}$ PMSF) (all from Fisher Scientific) with protease inhibitor (1x Roche Protease Inhibitor Cocktail Tablets) and incubated for $10 \mathrm{~min}$ at $4^{\circ} \mathrm{C}$ on a rocker. Cells were spun down again at $453 \mathrm{rcf}$ at $4^{\circ} \mathrm{C}$ for $5 \mathrm{~min}$, and supernatant was removed and resuspended in nuclear isolation buffer $(10 \mathrm{mM}$ Tris $\mathrm{pH} 7.5,10 \mathrm{mM} \mathrm{KCl}$, $0.5 \%$ Nonidet-P 40, $1 \mathrm{x}$ protease inhibitors, $1 \mathrm{mM}$ PMSF), before spinning again at $453 \mathrm{rcf}$ at $4^{\circ} \mathrm{C}$ for $10 \mathrm{~min}$. Supernatant was removed and the cell pellets were flash frozen in liquid nitrogen and stored at $-80^{\circ} \mathrm{C}$ until use. Cells were pooled from number of $\cong 300$ female and $\cong 300$ male embryos and thawed at $37^{\circ} \mathrm{C}$. 500 $\mu \mathrm{l}$ Turbo DNaseI buffer, $50 \mu \mathrm{l}$ Turbo DNaseI enzyme (2U/ $\mu \mathrm{l}), 10$ $\mu l$ superaseIN (Thermo Fisher), and 5 ul of $50 \mathrm{x}$ protease inhibitor were added to the cell suspension. Samples were incubated at $37^{\circ} \mathrm{C}$ for $45 \mathrm{~min}$ on a rocker. The nuclear lysates were further solubilized by adding $1 \%$ sodium lauryl sarcosine, $1 \mathrm{x}$ protease inhibitor, 0.3 $\mathrm{M}$ lithium chloride, $25 \mathrm{mM}$ EDTA, and $25 \mathrm{mM}$ EGTA to final concentrations (all of them from Sigma-Aldrich). Samples were mixed well and incubated again at $37^{\circ} \mathrm{C}$ for $15 \mathrm{~min}$. As a positive control, the highly expressed RNA U6 was used, and RNAse A treated samples as a negative control. U6 and TERRA-specific biotinylated probes (Integrated DNA Technologies IDT) were conjugated to streptavidin beads (MyOne streptavidin C1 Dyna beads, Invitrogen) for a 30-min incubation period at RT. The conjugated beads were mixed with the lysates and incubated at $55^{\circ} \mathrm{C}$ for $1 \mathrm{~h}$ before overnight incubation at $37^{\circ} \mathrm{C}$ in a hybridization chamber. After incubation, the beads were washed three times in wash buffer (10 mM Tris, pH 7.5, 0.3 M LiCl, 1\% LDS, 0.5\% Nonidet-P $40,1 \mathrm{x}$ protease inhibitor) at RT and then treated with DNase I digestion buffer, Turbo DNase I, $0.3 \mathrm{M} \mathrm{LiCl}$, protease inhibitors, and SuperaseIn (Thermo Fisher) at $37^{\circ} \mathrm{C}$ for $20 \mathrm{~min}$. Beads were resuspended and washed two more times in the wash buffer. For mass spectrometry (MS) analysis, proteins were eluted in Elution Buffer (10 mM Tris, $\mathrm{pH} 7.5,1 \mathrm{mM}$ EDTA) at $70^{\circ} \mathrm{C}$ for $4 \mathrm{~min}$.

\section{Nanoscale reverse phase chromatography and tandem mass spectrometry}

Mass spectrometry of iDRiP-derived proteins was performed at the Cornell University Proteomics and Mass Spectrometry facility. The nanoscale reverse phase liquid chromatography and tandem MS (nanoLC-MS/MS) analysis was carried out using an Orbitrap Fusion (Thermo Fisher Scientific, San Jose, CA) mass spectrometer equipped with a nanospray Flex Ion Source using high energy collision dissociation (HCD) and coupled with the UltiMate3000 RSLCnano (Dionex, Sunnyvale, CA). Each reconstituted sample, for both PGC and SOMA (18 $\mu \mathrm{l})$, was injected onto a PepMap C-18 RP nano trap column ( $3 \mu \mathrm{m}, 100 \mu \mathrm{m} \times 20 \mathrm{~mm}$, Dionex) with nanoViper Fittings at $20 \mu \mathrm{l} / \mathrm{min}$ flow rate for online desalting and then separated on a PepMap C-18 RP nano column ( $3 \mu \mathrm{m}, 75 \mu \mathrm{m} \times 25 \mathrm{~cm})$, and eluted in a 120 -min gradient of $5-35 \%$ acetonitrile in $0.1 \%$ formic acid at $300 \mathrm{~nL} / \mathrm{min}$. The instrument was operated in data-dependent acquisition mode using FT mass analyzer for one survey MS scan for selecting precursor ions followed by 3-s "Top Speed" datadependent HCD-MS/MS scans in Orbitrap analyzer for precursor peptides with 2-7 charged ions above a threshold ion count of 10000 with normalized collision energy of $38.5 \%$. For label-free protein analysis, one MS survey scan was followed by 3-s “Top 
Speed" data-dependent CID ion trap MS/MS scans with normalized collision energy of $30 \%$. Dynamic exclusion parameters were set at 1 within 45 s exclusion duration with $\pm 10 \mathrm{ppm}$ exclusion mass width. Two samples from each group, PGC and Soma, were analyzed in Orbitrap in the order of female followed by male samples for data acquisition. All data are acquired under Xcalibur 3.0 operation software and Orbitrap Fusion Tune 2.0 (Thermo-Fisher Scientific).

\section{NanoLC-MS/MS data processing, protein identification, and data analysis}

All MS and MS/MS raw spectra from each experiment were processed and searched using the Sequest HT search engine within the Proteome Discoverer 2.2 (PD2.2, Thermo). The default search settings used for relative protein quantitation and protein identification in PD2.2 searching software were as follows: two miscleavages for full trypsin with fixed carbamidomethyl modification of cysteine and oxidation of methionine and demaidation of asparagine and glutamine and acetylation on $\mathrm{N}$-terminal of protein were used as variable modifications. Identified peptides were filtered for maximum $1 \%$ false discovery rate using the Percolator algorithm in PD 2.2. The relative label-free quantification method within Proteome Discoverer 2.2 software was used to calculate the protein abundances. The intensity values of peptides, which were summed from the intensities values of the number of peptide spectrum matches, were summed to represent the abundance of the proteins. For relative ratio between the two groups, PGC female/male and Soma female/male, no normalization on total peptide amount for each sample was applied. Protein ratios are calculated based on pairwise ratio, where the median of all possible pairwise ratios was calculated between replicates of all connected peptides.

\section{Statistical analysis}

Statistical analyses were performed using GraphPad Prism version 6.00 for Macintosh (GraphPad Software, San Diego, CA, www.graphpad.com). Specific analyses are described within the text and the corresponding figures. Statistical significance was set at $P$ value of 0.05 .

\section{Results}

\section{Developmental changes in TERRA localization are} different in male and female primordial germ cells

Using RNA-FISH and 3D-SIM microscopy, we evaluated the presence of TERRA at three developmental stages (11.5 12.5, and 13.5 $\mathrm{dpc}$ ) in both sexes. The selection of these stages was based on the timing of sex determination in the mouse, the methylation status of PGCs, and the entrance into meiosis of female PGCs after $13.5 \mathrm{dpc}$ [24]. Quantitation of TERRA focus numbers was performed in both male and female SSEA-1-positive PGCs as well as in SSEA-1-negative cells (somatic cells). As a negative control, cells treated with RNAse A were used in which TERRA RNA should be completely degraded. A total number of 1352 PGCs and 973 somatic cells were analyzed. Female and male PGCs and somatic cells were obtained from at least three different pools at the different gestational ages. Pools consisted of PGCs from between 20 and 40 gonad pairs (1 pair per embryo).

Analysis of female PGCs and somatic cells showed the presence of discrete foci of TERRA (Figure 1A and C). The mean focus number observed in $11.5 \mathrm{dpc}$ female PGCs was $0.76 \pm 0.37$ per cell, rising to $3.88 \pm 0.73$ at $12.5 \mathrm{dpc}$ and $8.76 \pm 4.03$ at $13.5 \mathrm{dpc}$. Statistical analysis revealed significant differences among the three gestational ages $(P=0.001$ ANOVA; Figure $1 \mathrm{~B})$. Meanwhile, TERRA focus counts from female gonadal somatic cells at the same gestational ages revealed no statistical differences from $11.5 \mathrm{dpc}(19.76 \pm 1.143)$, $12.5 \mathrm{dpc}(19.86 \pm 1.52)$, and $13.5 \mathrm{dpc}(19.78 \pm 1.44$; Figure 1C and D). The number of TERRA foci in somatic cells was statistically significant compared to the neighboring germ cells at each gestational age. These results indicate that TERRA focus numbers alter with gestational in female PGCs but not in neighboring somatic cells.

In male PGCs, the dynamics of TERRA focus accumulation were very different to that seen in females. We were not able to detect TERRA signal in male $11.5 \mathrm{dpc}$ PGCs. Instead, the earliest detection TERRA in male PGCs was at $12.5 \mathrm{dpc}$ where we observed cells with either zero or one TERRA focus $(0.73 \pm 0.45$ foci/cell $)$. A statistically significant increase in the TERRA foci was observed in male $13.5 \mathrm{dpc}$ PGCs, where the mean focus number rose to $4.03 \pm 0.82(P=0.001 ;$ Figure $1 \mathrm{~A})$. Adjacent somatic cells of the male gonad showed TERRA focus numbers that were indistinguishable at all ages from that of female gonads, with no statistically significant differences found between sex or gestational age (11.5 dpc: $19.66 \pm 1.02$ foci/cell, $12.5 \mathrm{dpc}: 20.05 \pm 1.71 \mathrm{foci} / \mathrm{cell}$, and 13.5 dpc: $19.35 \pm 1.76$ foci/per cell; Figure 1D). These results indicate that in male PGCs the gestational age is a key factor in TERRA localization in PGCs but not in somatic cells. Comparison of TERRA foci numbers in both female PGCs and male PGCs revealed a sex bias. Compared to male PGCs, female PGCs showed significantly more TERRA foci at all the stages of development $(P=0.001$; Figure $1 \mathrm{~B})$, while no differences were observed at any gestational age between male and female somatic cells (Figure 1D).

\section{Differential transcription of TERRA in male and female primordial germ cells}

In human cell lines, transcription of TERRA is regulated by chromosome-specific promoters that are repressed by $\mathrm{CpG}$ methylation $[39,40]$. However, previous reports in mouse cell lines showed that almost all the TERRA transcripts are transcribed from the subtelomeric region of chromosome 18 , with some minor contribution from chromosome 9 [16]. However, nothing is known about TERRA transcription during this unique period of PGC development in which distinct changes in DNA methylation are occurring. Thus, we hypothesized that the loss of methylation that is a unique feature of PGCs may result in increased TERRA transcription, resulting in the increased localization of TERRA that we observed through this gestational time span. We performed qRT-PCR in isolated female and male PGCs at $11.5,12.5$, and $13.5 \mathrm{dpc}$ using primers designed to be chromosome-specific (Supplementary Table S1). As expected from the localization of TERRA, our results showed higher levels of TERRA expression in female PGCs compared to male PGCs at each gestational age (Figure 2A-O). Female PGCs showed TERRA expression at $11.5 \mathrm{dpc}$ from eight different chromosome subtelomeric regions (chromosomes 1, 2, 7, 9, 11,13, 17, and 18; Figure 2A, $\mathrm{B}, \mathrm{E}, \mathrm{G}, \mathrm{I}, \mathrm{J}, \mathrm{L}$, and $\mathrm{M}$, respectively), while in male PGCs at the same age, TERRA expression was confined to the chromosome 17 subtelomeric region (Figure 2L). At $12.5 \mathrm{dpc}$, we detected increased expression from chromosomes 5, 6, 8, 10, 15, and 19 in both female and male PGCs (Figure 2C, D, F, H, K, and N, respectively). The exception was the subtelomeric region of chromosome $\mathrm{X}$, from which transcription of TERRA was only detected for female PGCs (Figure 2O). Transcription of TERRA from the single $\mathrm{X}$ 
(A)
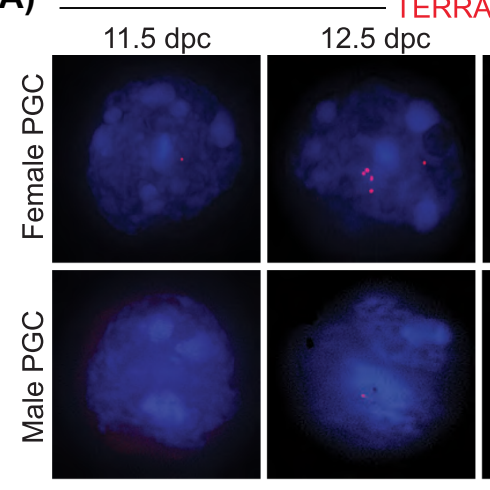

(C)

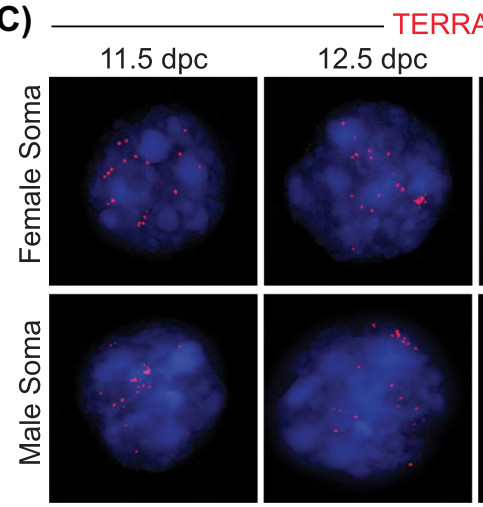

TERRA DAPI
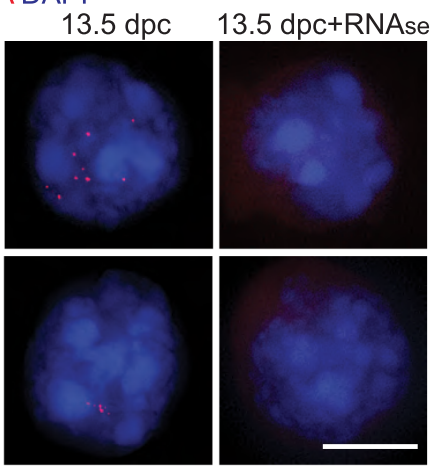

(B)

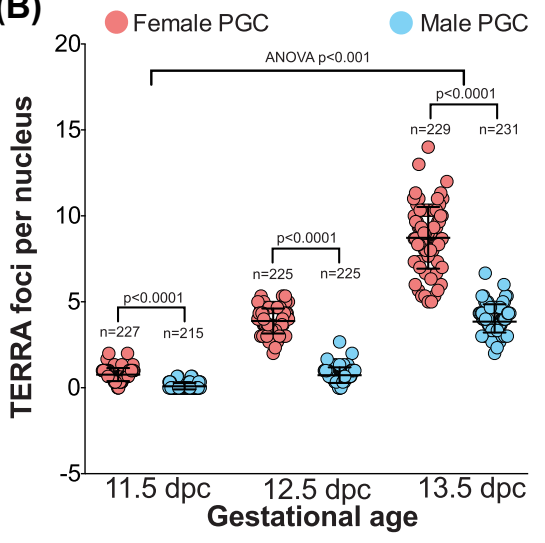

(D) Female Soma Male Soma

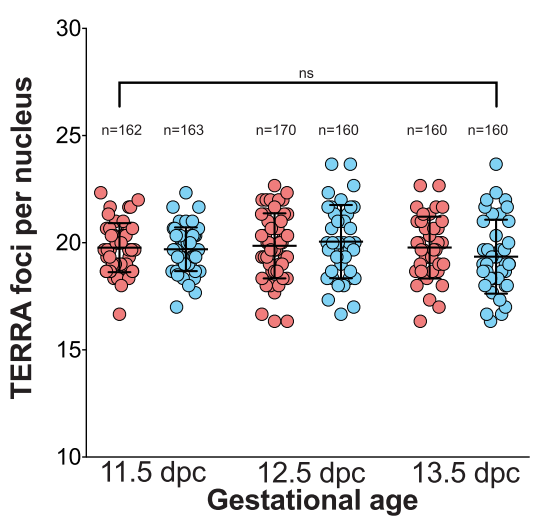

Figure 1. TERRA presence in mouse primordial germ cells (PGCs) differs by sex and developmental age. (A) Super-resolution imaging microscopy of TERRA RNA-FISH (red) on female and male PGCs at different stages of development $(11.5,12.5$, and 13.5 dpc). Negative controls correspond to 13.5 dpc female and male PGCs treated with RNAse before the RNA-FISH procedure. Scale bar $10 \mu \mathrm{m}$. (B) Quantitation of TERRA foci numbers on female and male PGCs at different stages of development $(11.5,12.5$, and $13.5 \mathrm{dpc})$. Statistical analysis was performed using ANOVA followed by Kruskal-Wallis multiple comparison analysis. (C) Superresolution imaging microscopy of TERRA RNA-FISH (red) on female and male somatic cells at different stages of development (11.5, 12.5, and 13.5 dpc). Negative controls used were $13.5 \mathrm{dpc}$ female and male somatic cell treated with RNAse before the RNA-FISH procedure. Scale bar $10 \mu \mathrm{m}$. (D) Quantitation of TERRA foci numbers on female and male somatic cells at different stages of development (11.5, 12.5, and $13.5 \mathrm{dpc})$. Statistical analysis was performed using ANOVA followed by Kruskal-Wallis multiple comparison analysis. Statistical significance was set at $P$ value of 0.05 .

chromosome of male PGCs only became evident at $13.5 \mathrm{dpc}$, but at a very low level compared to that of female PGCs at this gestational age (Figure 2O). Most TERRA transcription in $13.5 \mathrm{dpc}$ male PGCs arose from chromosomes 2 and 6 , and only in the case of the latter was there higher transcription in male PGCs than female PGCs (Figure $2 \mathrm{~B}$ and $\mathrm{D}$ ). Indeed, at all gestational ages, we observed higher transcription of TERRA at each telomere in female PGCs, except for the subtelomeric region of chromosomes 2, 6, and 10. These results indicate that the transcription of TERRA is differentially regulated in the male and female germ line. Furthermore, and in contrast to previous results, we observed that TERRA is transcribed from multiple telomeres in a gestational and sex-dependent manner.

TERRA and telomerase reverse transcriptase colocalization and expression are regulated by gestational age and sex

There is a lot of controversy regarding the role of TERRA in the regulation of telomerase reverse transcriptase (TERT), the catalytic subunit of telomerase. The most common idea suggests that TERRA expression downregulates or inhibits TERT [20, 41]. Previous reports have indicated that there is decay in the Tert expression with age in male germ cells, including PGCs $[42,43]$. Confounding this, however, there are suggestions that high levels of telomerase are required to maintain spermatogonia in their undifferentiated state [44]. Using SIM microscopy, we evaluated the colocalization of TERT and TERRA at $13.5 \mathrm{dpc}$, and plotted the percent colocalization in PGCs from both sexes (percentages were obtained from the number of TERRA-TERT foci divided by the total TERRA foci, and multiplied by 100 ) (Figure $3 \mathrm{~A}$ and $\mathrm{B}$ ). In female PGCs, $63.5 \%$ of the TERRA foci colocalized with TERT but only the $36.1 \%$ in 13.5 male PGCs (Figure 3C; $P=0.0001$ ).

We evaluated the expression of Tert using qRT-PCR, and showed a statistically significant decrease of Tert expression from 11.5 to $13.5 \mathrm{dpc}$ in both male and female PGCs (Figure 3D; $P=0.001$ ). Consistently, however, Tert expression was significantly higher in male PGCs than in age-matched female PGCs (Figure 3D). Thus, the increasing TERRA focus count with gestational age and the relatively increased number of TERRA foci/cell in female germ cells compared to male germ cells are both inversely correlated with Tert 
(A) CHROMOSOME 1

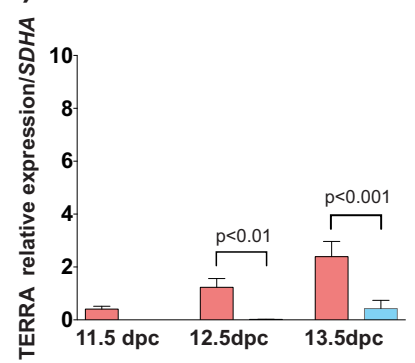

(D) CHROMOSOME 6

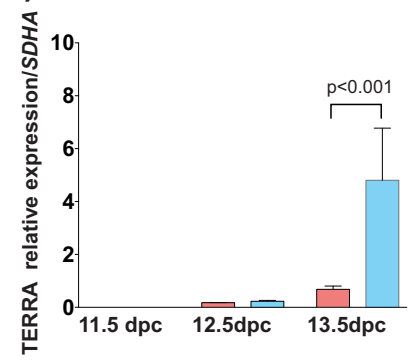

(G) CHROMOSOME 9

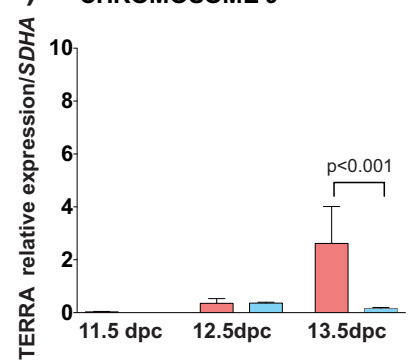

(J) CHROMOSOME 13

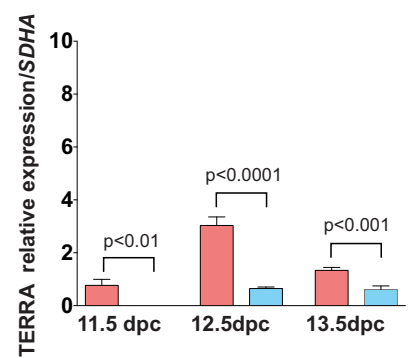

(M) CHROMOSOME 18

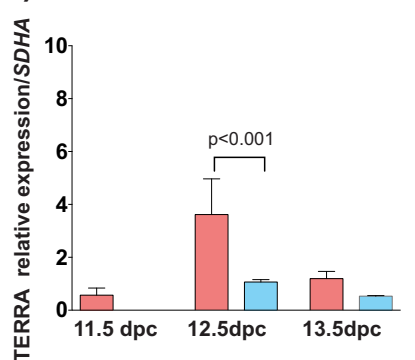

(B) CHROMOSOME 2

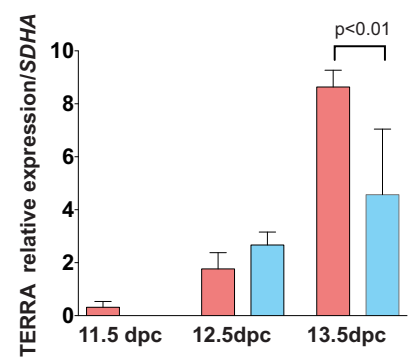

(E) CHROMOSOME 7

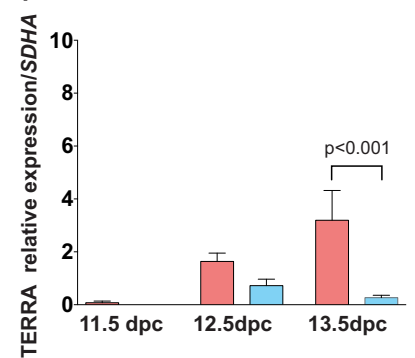

(H) CHROMOSOME 10

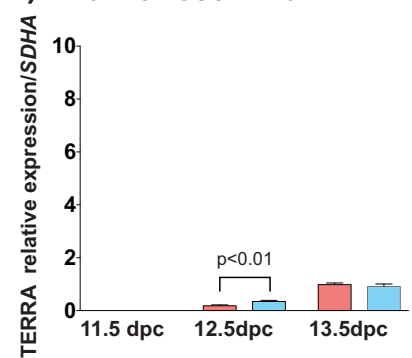

(K) CHROMOSOME 15

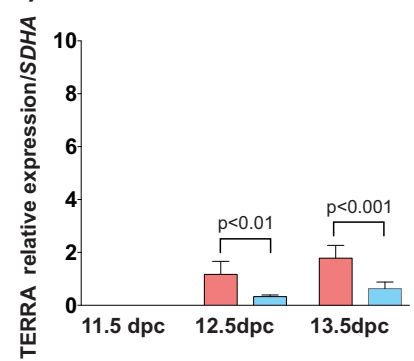

(N) CHROMOSOME 19

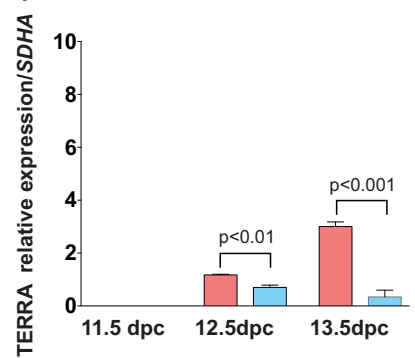

(C) CHROMOSOME 5

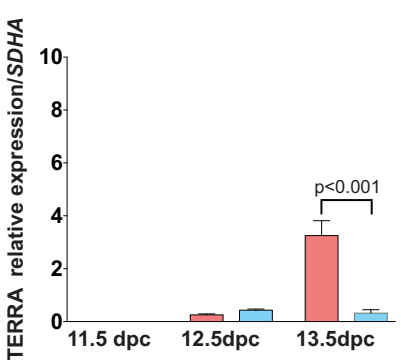

(F) CHROMOSOME 8

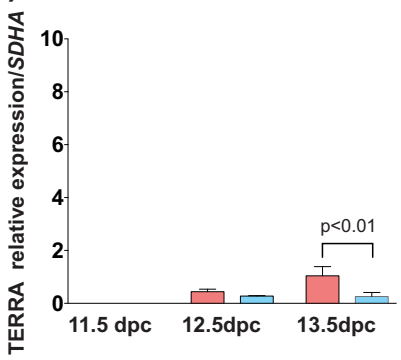

(I) CHROMOSOME 11

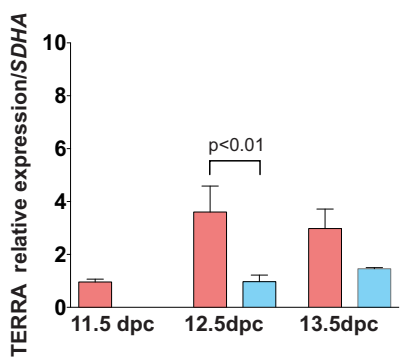

(L) CHROMOSOME 17

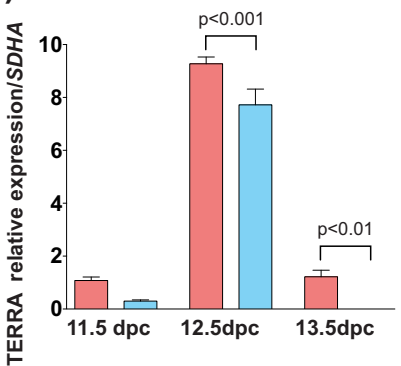

(O) CHROMOSOME $X$

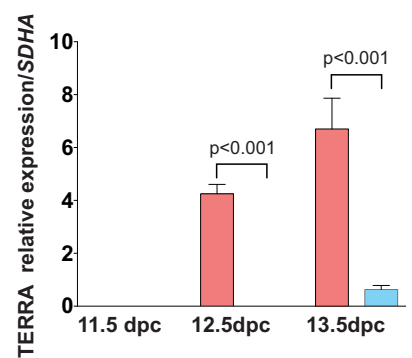

Figure 2. TERRA expression is different depending on gestational age and sex. (A to O) qRT-PCR analysis of the expression of TERRA from subtelomeric regions of chromosome $1,2,5,6,7,8,9,10,11,13,15,17,18,19$, and X. The results are expressed as relative TERRA expression normalized to Sdha at the different developmental ages $(11.5,12.5$, and $13.5 \mathrm{dpc})$. Columns in red represent female PGCs and blue represent male PGCs Statistical analysis was performed using one-way ANOVA with multiple comparison. Statistical significance was set at $P$ value of 0.05 . 


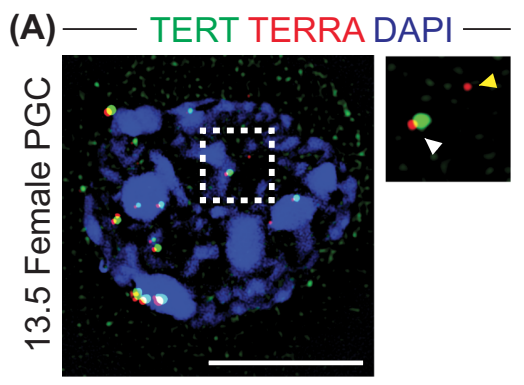

(C) $\square$ Female PGC $\square$ Male PGC

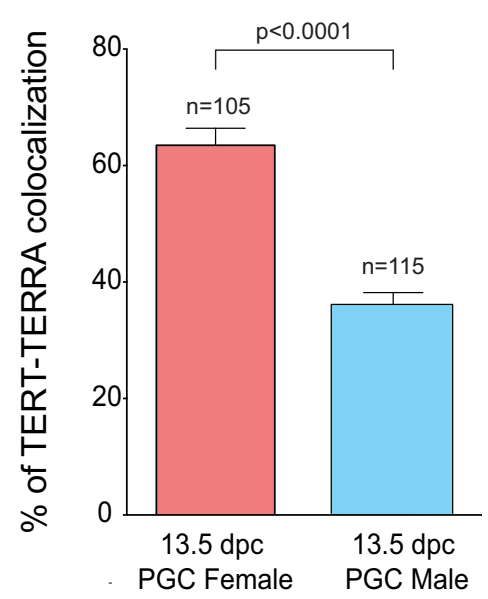

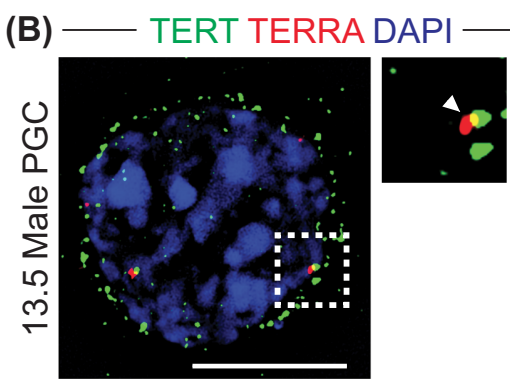

(D)

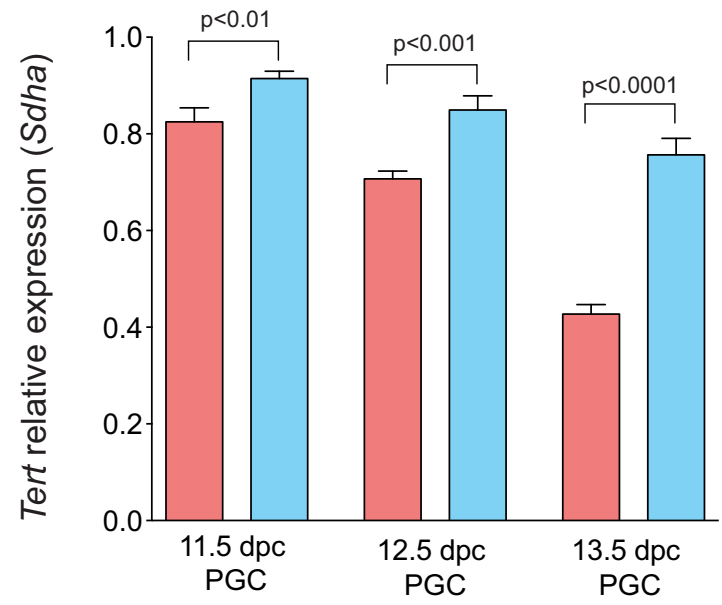

Figure 3. TERRA and the catalytic subunit of the enzyme telomerase (TERT) colocalization and expression are regulated by gestational age and sex. (A) Superresolution imaging microscopy of TERT (green) immunofluorescence followed by TERRA RNA-FISH (red) on female 13.5 dpc primordial germ cells (PGCs). Scale bar $10 \mu \mathrm{m}$; in the inset, the white arrowhead shows TERRA-TERT interaction, and the yellow arrowhead shows only TERRA foci. (B) Super-resolution imaging microscopy of TERT (green) immunofluorescence followed by TERRA RNA-FISH (red) on male $13.5 \mathrm{dpc}$ PGCs. Scale bar $10 \mu \mathrm{m}$; in the inset the white arrowhead shows TERRA-TERT interaction, and the yellow arrowhead shows only TERRA foci. (C) Analysis of the percentage of TERRA-TERT colocalization on female and male PGCs. Percentages were obtained from the number of TERRA-TERT foci divided by the total TERRA foci, and multiplied by 100. Statistical analysis was performed with unpaired t-test. $P$ value was set at 0.05 . (D) qRT-PCR analysis of the expression of Tert at different stages of development (11.5, 12.5, and $13.5 \mathrm{dpc}$ ). The results are expressed as the Tert relative expression normalized by Sdha. Red columns indicated the analysis performed in female PGCs and blue columns indicate the analysis performed in male PGCs. Statistical analysis was performed using one-way ANOVA with multiple comparisons. Statistical significance was set at $P$ value of 0.05 .

expression, which declines with gestational age and which is higher in male PGCs.

\section{The TERRA interactome is sexually dimorphic}

To understand TERRA function, it is important to identify key TERRA interacting proteins in the cell type of interest. Given that we obtain so few PGCs at specific developmental ages, we focused on only one gestational age in which to investigate the TERRA interactome in PGCs and somatics cells: $13.5 \mathrm{dpc}$. We performed iDRiP using three million PGCs from both male and female gonads, along with comparable neighboring somatic cells. A total of 48 proteins were identified in female PGCs and 26 in male PGCs, of which $32(55.2 \%)$ were unique to female PGCs and 10 (17.2\%) were specific for male PGCs (Figure 4A and B). The remaining 16 $(27.6 \%)$ TERRA-associated proteins were shared between female and male PGCs (Figure 4A). Using the relative label-free quantification method within Proteome Discoverer 2.2 software, we calculated the protein abundances. The intensity values of peptides, which were summed from the intensities values of the number of peptide spectrum matches, were summed to represent the abundance of the proteins. The results of these relative label-free quantitations showed different relative levels of protein between female and male PGCs (Figure 4B) (Supplementary Table S2). Gene ontology analysis using GO Panther software revealed enrichment for nuclear acid binding proteins, transcription factors, transferases, and cytoskeletal proteins. Analysis by biological pathway showed enrichment for Alzheimer disease, apoptosis signaling pathway, cytoskeletal regulation by Rho GTPase, DNA replication, Huntington disease, and Parkinson disease.

We also analyzed the TERRA interactome in gonadal somatic cells, and observed far higher numbers of TERRA interacting proteins, but with greater number of proteins in male somatic cells than in female somatic cells (Figure 4C). A total of 118 proteins were obtained from female somatic cells and 158 were obtained from male somatic cells (Figure 4C), with 31 (16.4\%) and 71 $(37.6 \%)$ proteins, respectively, being unique to one sex. Overall, female and male somatic cells shared 87 (46\%) TERRA interacting proteins (Figure 4D). Similar to PGCs, we used the relative label-free quantification method to compare the relative abundance of proteins in both female and male somatic cells. Our results showed a different 
(A)

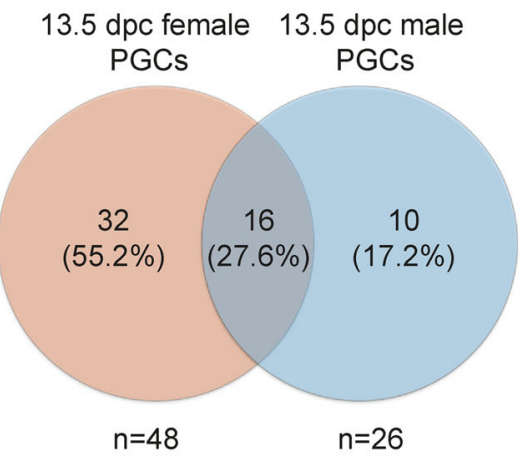

(B)

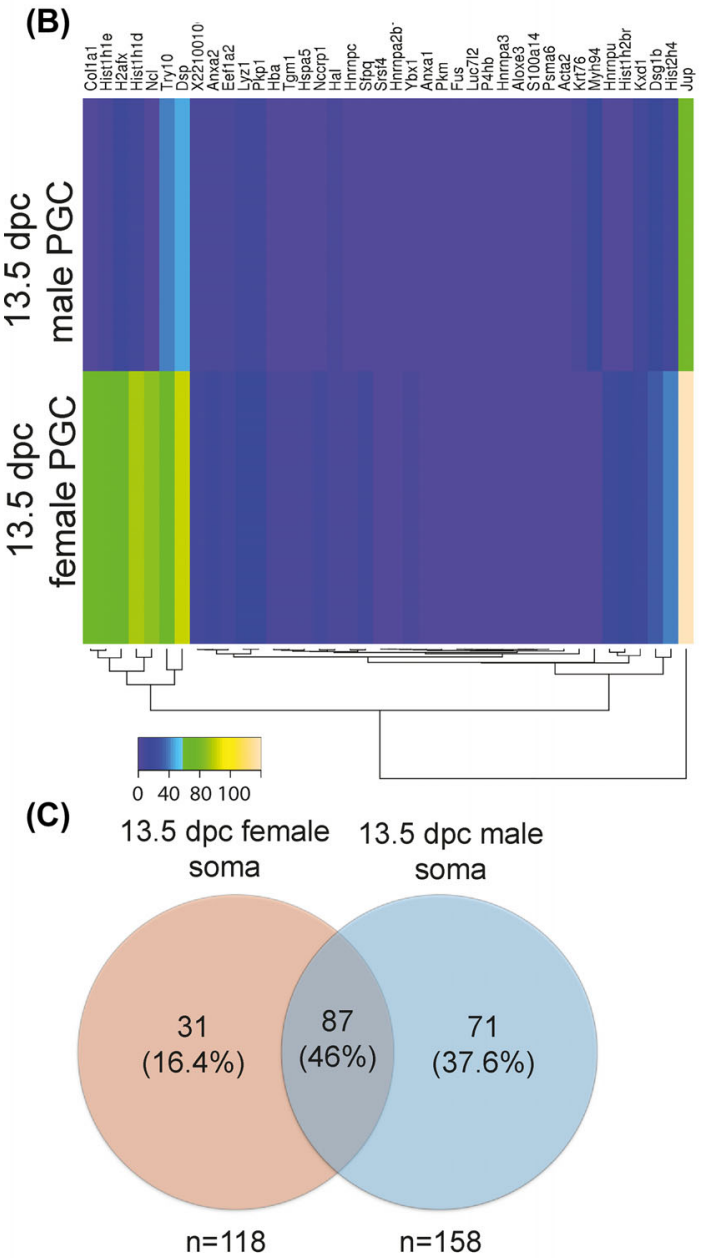

(D)
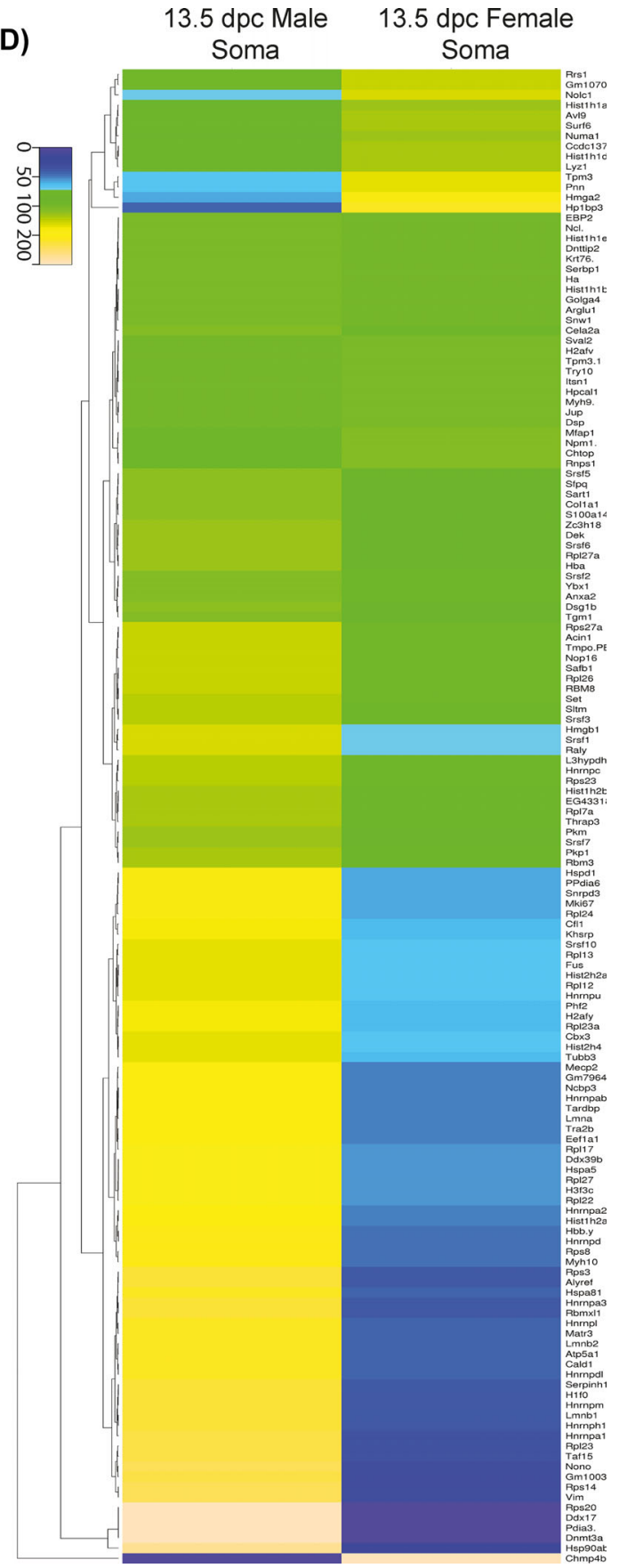

Figure 4. The TERRA interactome of the gonad is sexually dimorphic. (A) Analysis of the male and female PGCs protein distribution obtained from iDRiP. (B) Heat map analysis of the relative protein concentration in PGCs obtained by iDRiP-mass spec. The relative label-free quantification method within Proteome Discoverer 2.2 software was used to calculate the protein abundances. (C) Analysis of the male and female somatic protein distribution obtained from iDRiP. (D) Heat map analysis of the relative protein concentration in somatic obtained by iDRiP-mass spec. The relative label-free quantification method within Proteome Discoverer 2.2 software was used to calculate the protein abundances.

distribution of the relative protein abundance in female gonads compared to male gonads (Figure 4D, and Supplementary Table S3).

\section{SFPO interacts with TERRA in primordial germ cells}

To validate the interactions of TERRA detected by iDRiP, we used two different approaches. First, we immunolocalized the protein of interest on $13.5 \mathrm{dpc}$ ovaries and testis, and secondly, we colocal- ized TERRA and the protein on isolated cells. Based on our iDRIPidentified interacting proteins, we decided to analyze proteins with the most extreme ratios between male and female. After antibody testing and standardization, we selected two proteins for validation: one for PGCs and another for somatic cells. The splicing factor, proline- and glutamine-rich (SFPQ) showed one of the lowest iDRiP male/female ratios (0.01) (Supplementary Table S3). Using antibodies against the germ cell lineage marker VASA (DDX4/MVH) and 

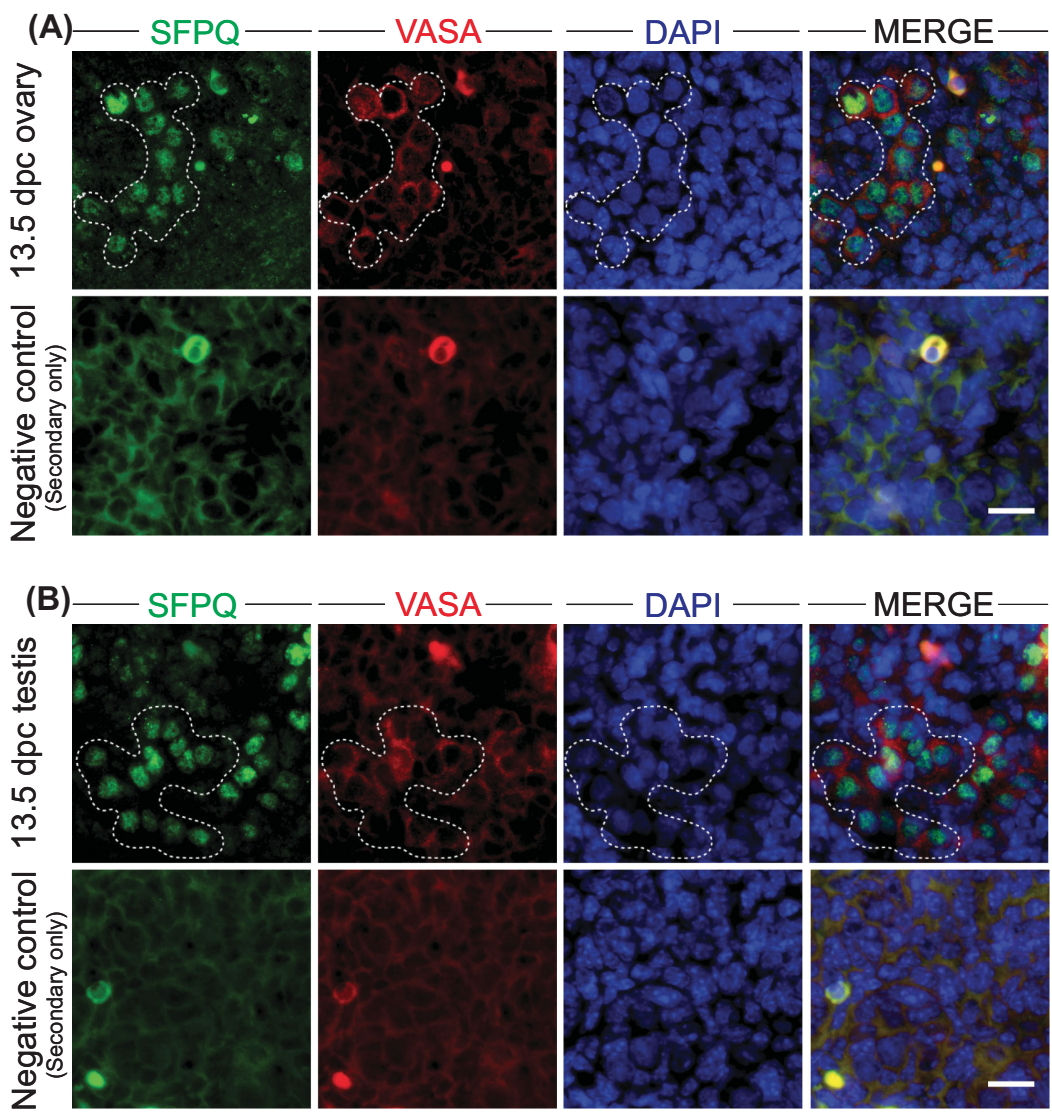

(C) -SFPQ TERRA DAPI-

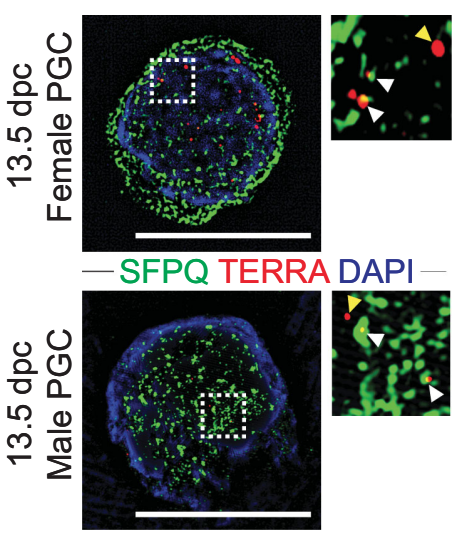

(D)

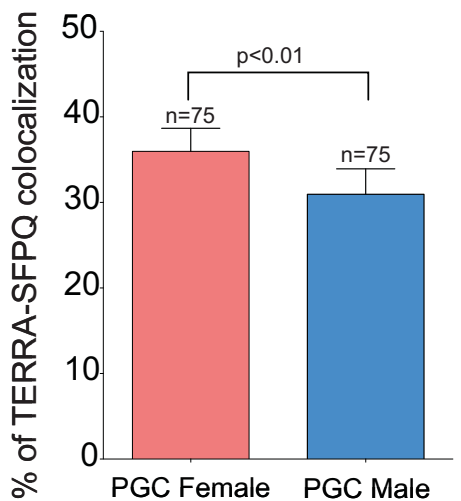

Figure 5. SFPQ interacts TERRA on PGCs. (A) Immunofluorescence on 13.5 dpc ovary with antibodies against SFPQ (green), VASA (red), and DAPI. Scale bar $20 \mu \mathrm{m}$. (B) Immunofluorescence on $13.5 \mathrm{dpc}$ testis with antibodies against SFPQ (green), VASA (red), and DAPI. Scale bar $20 \mu \mathrm{m}$. (C) Super-resolution imaging microscopy of SFPQ (green) immunofluorescence followed by TERRA RNA-FISH (red) on female and male 13.5 dpc primordial germ cells (PGCs). Scale bar $10 \mu \mathrm{m}$; in the inset the white arrowhead shows TERRA-SFPQ interaction, yellow arrowhead shows only TERRA foci. (D) Analysis of the percentage of colocalization of TERT-TERRA on male and female PGCs. Percentages were obtained from the number of TERRA-SFPO foci divided by the total TERRA foci, and multiplied by 100. Statistical analysis was performed using t-test analysis. Statistical significance was set at $P$ value of 0.05 .

SFPQ, we first determined the specific localization to the nucleus in both female and male PGCs by IF on tissue sections (Figure 5A and B). We observed the presence of SFPQ signal on the nuclei of the VASA-positive cells (PGCs), but not in the VASA-negative cells (somatic cells). Thereafter, and to confirm the interaction detected with iDRiP, we performed IF followed by TERRA RNA-FISH to evaluate the cololocalization of SPFQ and TERRA on isolated female and male $13.5 \mathrm{dpc}$ PGCs. Since the number of TERRA foci varies within female/male, we compared the percentages of colocalizing foci between male and female PGCs. Percentages were obtained from the number of TERRA-SFPQ foci divided by the total TERRA foci, and multiplied by 100 . Interestingly, we observed colocalization in both female and male PGCs (Figure 5C). However, female PGCs showed increased percentage of colocalization of TERRASFPQ $(36 \%)$ compared to male PGCs $(30 \%)$ (Figure 5D; $P=0.01$ ), suggesting although TERRA interacts with SFPQ in both sexes, there is an increased interaction in female PGCs.

\section{NONO interacts with TERRA in somatic cells of the fetal gonad}

Similar to our approach for SFPQ as mentioned above, we selected one TERRA-interacting protein to validate on somatic cells. We analyzed the localization and interaction of TERRA with non-POU domain-containing octamer-binding protein (NONO). NONO was previously described as TERRA interacting protein in cell lines [17]. First, we evaluated the localization of NONO in female and male gonads, the use of VASA antibody allowed us to identify PGCs from somatic cells. In both sexes, we observed a positive NONO staining in somatic cells with a clear absence of NONO staining on the nuclei of the VASA positive cells (Figure 6A and B). Using IF followed by TERRA RNA-FISH, we evaluated the colocalization of NONO with TERRA on isolated somatic cells (Figure 5C). Colocalization analysis showed that the $42 \%$ of the TERRA foci colocalized with NONO on 13.5 female somatic cells; however, on the male somatic only the $25 \%$ of the TERRA foci colocalized with NONO (percentages were obtained from the number of TERRA-NONO foci divided by the total TERRA foci, and multiplied by 100) (Figure 5C and D; $P=0.01)$. These results suggest that the colocalization of TERRA and NONO is restricted to the somatic cell lineages of the fetal gonad.

\section{Discussion}

To date, there is a very limited understanding of TERRA biology, especially as it pertains to germ cells. Herein, we describe for first time 

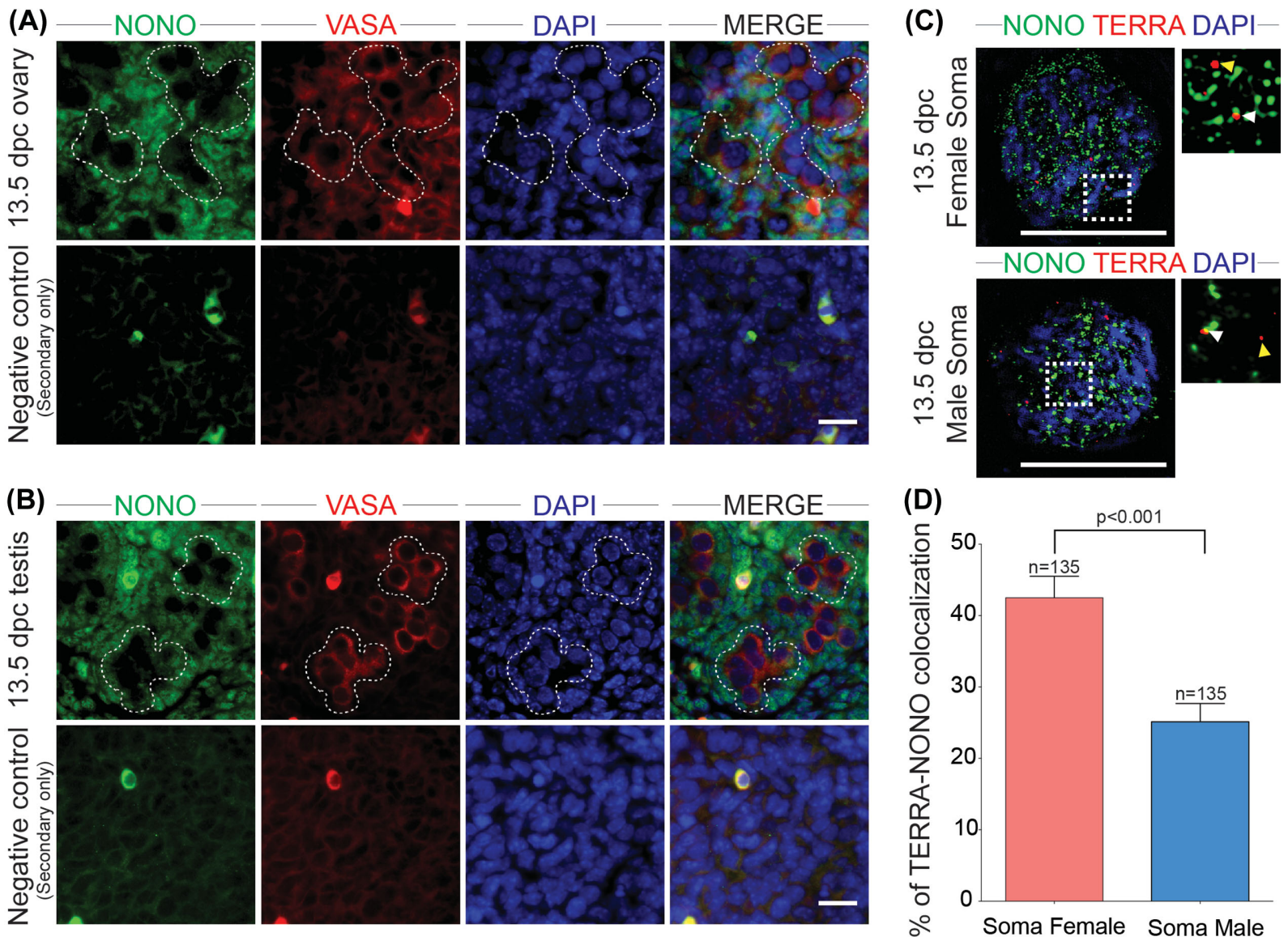

Figure 6. NONO interacts with TERRA on gonadal somatic cells. (A) Immunofluorescence on 13.5 dpc ovary with antibodies against NONO (green), VASA (red), and DAPI. Scale bar $20 \mu \mathrm{m}$. (B) Immunofluorescence on $13.5 \mathrm{dpc}$ testis with antibodies against NONO (green), VASA (red), and DAPI. Scale bar $20 \mu \mathrm{m}$. (C) Super-resolution imaging microscopy of NONO (green) immunofluorescence followed by TERRA RNA-FISH (red) on female and male 13.5 dpc somatic cells. Scale bar $10 \mu \mathrm{m}$; in the inset the white arrowhead shows TERRA-NONO interaction, the yellow arrowhead shows only TERRA foci. (D) Analysis of the percentage of colocalization of TERRA-NONO on male and female somatic cells. Percentages were obtained from the number of TERRA-NONO foci divided by the total TERRA foci, and multiplied by 100 . Statistical analysis was performed using t-test analysis. Statistical significance was set at $P$ value of 0.05 .

the localization, expression, and the protein interactions of TERRA in PGCs during the critical period of epigenetic reprogramming and the onset of sex determination. TERRA transcription, at least in human cells, was described to be regulated by methylation status $[18,45]$. During PGC development, genome-wide DNA demethylation in mid-gestation results in the lowest levels of methylated DNA at around $13 \mathrm{dpc}[24,46]$. Therefore, we hypothesized that the transcription and localization of TERRA within PGCs will increase inversely to the drop in DNA methylation. At the same time, this period is associated with gonadal sex determination and the concomitant entry of female PGCs into meiosis, with male PGCs entering a period of mitotic quiescence. Thus, we suggest that this period of development would provide key differences in TERRA regulation between the male and female germ lineages. Our results showed that both TERRA focus distribution and TERRA transcription increase with gestational age in both female and male PGCs. However, the increases are significantly higher in PGCs isolated from ovaries compared to those obtained from testis, and there is a delay by 1 day in the onset of TERRA transcription in males.

Sexual dimorphism in the epigenetic marker and DNA methylation patterns in PGCs has been extensively studied at different stages of gestation in the mouse $[24,25]$. In both sexes, the lowest levels of genome-wide methylation are observed at $13.5 \mathrm{dpc}$, but the recovery of the epigenetic marks takes longer in the female germ line compared to male [47]. Thus, the increased TERRA localization may be highly influenced by the onset of prophase I in the female germ line but we cannot discard the role of the changes in methylation status. Indeed, since one proposed function of TERRA is to regulate/suppress DNA damage repair processes, and since prophase I is characterized by the induction and orchestrated repair of hundreds of DNA double-strand breaks (DSBs), it is tempting to speculate that one role of TERRA is to prevent DSB induction/repair at telomeres and instead to direct DSB events to more proximal chromosomal locations. The purpose of prophase I DSB induction/repair is to generate a highly regulated number of crossovers that serve as tethering points to maintain homologous chromosome interactions until the first meiotic division. Thus, the placement of DSB events at telomeres would not be ideal for this purpose.

Interestingly, TERRA focus numbers in both male and female PGCs are significantly lower than in somatic cells, and represent a frequency that is less than a quarter of the number of telomeres present in the nucleus. In the soma, by contrast, only half the diploid number of chromosomes (40 in mouse) appears to be associated with a TERRA focus. It is important to note that somatic cells of 
the gonad do not undergo erasure of epigenetic marks, indicating that TERRA transcription in PGCs and somatic cells at these particular stages of development is likely to be regulated by different mechanisms.

Controversial results have been published about the expression of TERRA and Tert, where it has been described that TERRA either recruits TERT to the telomere to promote its enzymatic function or conversely TERRA is acting as a competitive inhibitor that is competing for access to telomeric DNA [20, 41]. Our results showed that in PGCs the expression of TERRA increases during development; however, Tert decreases in relation to gestational age in agreement with previous reports $[42,43,48]$. Our results demonstrate intermittent colocalization of TERT and TERRA, and also showed that when transcription of TERRA increases the Tert transcription decreases. However, more studies analyzing the interaction of TERRA with TERT are required to evaluate whether TERRA affects the enzymatic activity or the transcription of Tert in PGCs.

A previous study had investigated TERRA-protein interactions in MEFs using a pre-existing RNA-IP technique [38] and only 41 proteins were identified as part of the TERRA interactome. Analysis of TERRA interacting proteins has also been performed using SILAC-labeled nuclear cell lysates, and pooled results from two independent pull downs showed approximately 924 interacting proteins [37]. More recently, iDRiP was used to examine TERRA interactions in $15 \times 10^{7}$ mouse embryonic stem cells and the authors reported 134 interacting proteins ranging from components of the shelterin complex to chromatin-associated proteins, DNA repair proteins, and cell cycle regulators, to name just a few $[17,21]$. In all these reports, the authors used cultured somatic cells or ESCs, allowing for high cell input $(\approx 30$ million cells). By contrast, the current study analyzed TERRA interacting proteins starting with 3 million PGCs from each sex and an equivalent number of somatic cells, representing cell purifications from 300 pups for each sex. Despite the low input, 48 proteins were identified in female PGCs and 26 in male PGCs. $37.5 \%$ of these proteins were shared with the iDRiP study of Chu et al. using ES cells [17]. Interestingly, the SFPQ-TERRA interaction that we identify in female and male PGCs was not observed in ES cells suggesting potential specificity of this interaction for germ cells. By contrast, in somatic cells of the gonad, we identified NONO as an interactor of TERRA, as well several heterogeneous ribonucleoproteins, histones, chromatin-associated proteins, RNAP II and DNA repair proteins. These interacting proteins were also identified in the Chu et al. paper. The comparison between our data and previous reports suggests that there are interactions conserved in different cell types; however, TERRA also have specific protein interactions depending of the cell type and at least in PGCs the sex is another determinant factor.

To validate our iDRIP data, we chose to examine further one PGC-specific (SFPQ) and somatic cell-specific (NONO) interacting protein. We did not observe clear differences in protein localization on histology sections in $13.5 \mathrm{dpc}$ ovary and $13.5 \mathrm{dpc}$ testis. We analyzed the colocalization of TERRA-SFPQ and TERRA-NONO; in both cases the percentage of colocalization of TERRA-protein was higher in females compared to males, indicating that at least at this specific point of development, the interaction/function of the TERRA-protein complex is different. SFPQ is DNA- and RNAbinding protein, while NONO is an RNA splicing factor [49]. Both proteins have been implicated in a range of DNA/RNA metabolic processes, including ssDNA invasion to generate a D-loop, nonhomologous end joining, and mRNA processing and stabilization [50]. However, their function in the developing mouse gonad including meiosis, and particularly in connection with TERRA, remains unknown.

Taken together, herein we described for first time the presence of TERRA in mouse PGCs. Our results also showed that in mouse PGCs TERRA foci number, expression, and protein interactions depend on the gestational age and sex suggesting that the role of TERRA telomere dynamics is related to sexually dimorphic changes in germ cell development with age.

\section{Supplemental Data}

Supplementary data are available at BIOLRE online.

Supplementary Table S1. TERRA and specific subtelomeric chromosome primers.

Supplementary Table S2. PGCs protein ratios obtained from iDRiP $(\mathrm{m} / \mathrm{f})$.

Supplementary Table S3. Somatic cells protein ratios obtained from $\operatorname{iDRiP}(\mathrm{m} / \mathrm{f})$.

Supplementary Figure S1. SSEA-1 staining on 13.5 dpc ovary and testis. (A) Immunofluorescence on $13.5 \mathrm{dpc}$ ovary with antibodies against SFPQ (green, upper panel) NONO (green, lower panel), SSEA-1 (red), and DAPI. (B) Immunofluorescence on 13.5 dpc testis with antibodies against SFPQ (green, upper panel), NONO (green, lower panel), SSEA-1 (red), and DAPI. Scale bar $20 \mu \mathrm{m}$.

\section{Acknowledgments}

We are grateful to Dr Jen Grenier, Dr Rita Reig-Viader, Dr Anand Minajigi, and Dr Jeannie Lee for their advice and protocol sharing to perform the qRTPCRs, RNA-FISH, and iDRiP. We thank Dr Sheng Zhang and Dr Ruchika Bhawal from Cornell Proteomics and Mass Spectrometry facility for his advice in development of mass spectrometry experiments. We are also thankful to Dr Stephen Gray, Dr Kathryn Grive, Carolyn Milano, Amanda Touey, and Jeffrey Pea for providing critical feedback for the manuscript.

\section{Author contribution}

MAB-E and PEC designed experiments. MAB-E, SLM, and AB-F carried out experiments. MAB-E, SLM, and PEC analyzed and interpreted data. MAB-E and PEC wrote the manuscript.

Conflict of Interest: The authors have declared that no conflict of interest exists.

\section{References}

1. Maicher A, Lockhart A, Luke B. Breaking new ground: digging into TERRA function. Biochim Biophys Acta 2014; 1839:387-394.

2. Ozturk S. Telomerase activity and telomere length in male germ cells. Biol Reprod 2015; 92;53.

3. Hemann MT, Strong MA, Hao LY, Greider CW. The shortest telomere, not average telomere length, is critical for cell viability and chromosome stability. Cell 2001; 107:67-77.

4. Turner S, Hartshorne GM. Telomere lengths in human pronuclei, oocytes and spermatozoa. Mol Hum Reprod 2013; 19:510-518.

5. Ferlin A, Rampazzo E, Rocca MS, Keppel S, Frigo AC, De Rossi A, Foresta C. In young men sperm telomere length is related to sperm number and parental age. Hum Reprod 2013; 28:3370-3376.

6. Reig-Viader R, Garcia-Caldes M, Ruiz-Herrera A. Telomere homeostasis in mammalian germ cells: a review. Chromosoma 2016; 125:337351.

7. Blasco MA. Telomeres and human disease: ageing, cancer and beyond. Nat Rev Genet 2005; 6:611-622. 
8. Mason JMO, McEachern MJ. Mild telomere dysfunction as a force for altering the adaptive potential of subtelomeric genes. Genetics 2018; 208:537-548.

9. Schoeftner S, Blasco MA. Developmentally regulated transcription of mammalian telomeres by DNA-dependent RNA polymerase II. Nat Cell Biol 2008; 10:228-236.

10. Hu C, Rai R, Huang C, Broton C, Long J, Xu Y, Xue J, Lei M, Chang $\mathrm{S}$, Chen Y. Structural and functional analyses of the mammalian TIN2TPP1-TRF2 telomeric complex. Cell Res 2017; 27:1485-1502.

11. Kung JT, Colognori D, Lee JT. Long noncoding RNAs: past, present, and future. Genetics 2013; 193:651-669.

12. Jain D, Cooper JP. Telomeric strategies: means to an end. Annu Rev Genet 2010; 44:243-269.

13. Sfeir A, de Lange T. Removal of shelterin reveals the telomere endprotection problem. Science 2012; 336:593-597.

14. Diman A, Decottignies A. Genomic origin and nuclear localization of TERRA telomeric repeat-containing RNA: from darkness to dawn. FEBS J 2018; 285:1389-1398.

15. Rippe K, Luke B. TERRA and the state of the telomere. Nat Struct Mol Biol 2015; 22:853-858.

16. Lopez de Silanes I, Graña O, Luigia De Bonis M, Dominguez O, Pisano DG, Blasco MA. Identification of TERRA locus unveils a telomere protection role through association to nearly all chromosomes. Nat Commun 2014; 5:4723.

17. Chu HP, Cifuentes-Rojas C, Kesner B, Aeby E, Lee HG, Wei C, Oh HJ, Boukhali M, Haas W, Lee JT. TERRA RNA antagonizes ATRX and protects telomeres. Cell 2017; 170:86-101.e16.

18. Deng Z, Campbell AE, Lieberman PM. TERRA, CpG methylation, and telomere heterochromatin: lessons from ICF syndrome cells. Cell Cycle 2010; 9:69-74.

19. Morris KV, Mattick JS. The rise of regulatory RNA Nat Rev Genet 2014; 15:423-437.

20. Redon S, Reichenbach P, Lingner J. The non-coding RNA TERRA is a natural ligand and direct inhibitor of human telomerase. Nucleic Acids Res 2010; 38:5797-5806.

21. Chu HP, Froberg JE, Kesner B, Jung Oh H, Ji F, Sadreyev R, Pinter SF, Lee JT. PAR-TERRA directs homologous sex chromosome pairing. Nat Struct Mol Biol 2017; 24:620-631.

22. Reig-Viader R, Vila-Cejudo M, Vitelli V, Buscà R, Sabaté M, Giulotto E, Caldés MG, Ruiz-Herrera A. Telomeric repeat-containing RNA (TERRA) and telomerase are components of telomeres during mammalian gametogenesis. Biol Reprod 2014; 90:103.

23. Reig-Viader R, Capilla L, Vila-Cejudo M, Garcia F, Anguita B, GarciaCaldés M, Ruiz-Herrera A. Telomere homeostasis is compromised in spermatocytes from patients with idiopathic infertility. Fertil Steril 2014; 102:728-738.e1.

24. Saitou M, Yamaji M. Primordial germ cells in mice. Cold Spring Harb Perspect Biol 2012; 4, doi: 10.1101/cshperspect.a008375.

25. Saitou M, Yamaji M. Germ cell specification in mice: signaling, transcription regulation, and epigenetic consequences. Reproduction 2010; 139:931-942.

26. Saitou M, Payer B, Lange UC, Erhardt S, Barton SC, Surani MA. Specification of germ cell fate in mice. Philos Trans Roy Soc Lond B: Biol Sci 2003; 358:1363-1370.

27. McLaren A, Lawson KA. How is the mouse germ-cell lineage established? Differentiation 2005; 73:435-437.

28. Pesce M, De Felici M. Purification of mouse primordial germ cells by MiniMACS magnetic separation system. Dev Biol 1995; 170:722-725.

29. Brieño-Enriquez MA, García-López J, Cárdenas DB, Guibert S, Cleroux E, Děd L, de Dios Hourcade J, Pěknicová J, Weber M, del Mazo J Exposure to endocrine disruptor induces transgenerational epigenetic deregulation of microRNAs in primordial germ cells. PLoS One 2015; 10:e0124296.

30. McClive PJ, Sinclair AH. Rapid DNA extraction and PCR-sexing of mouse embryos. Mol Reprod Dev 2001; 60:225-226.

31. Reig-Viader R, Brieño-Enríquez MA, Khoriauli L, Toran N, Cabero L, Giulotto E, Garcia-Caldés M, Ruiz-Herrera A. Telomeric repeat- containing RNA and telomerase in human fetal oocytes. Hum Reprod $2013 ; 28: 414-422$.

32. Azzalin CM, Reichenbach P, Khoriauli L, Giulotto E, Lingner J. Telomeric repeat containing RNA and RNA surveillance factors at mammalian chromosome ends. Science 2007; 318:798-801.

33. Feretzaki M, Lingner J. A practical qPCR approach to detect TERRA, the elusive telomeric repeat-containing RNA. Methods 2017; 114:3945 .

34. van den Bergen JA, Miles DC, Sinclair AH, Western PS. Normalizing gene expression levels in mouse fetal germ cells. Biol Reprod 2009; 81:362-370.

35. Livak KJ, Schmittgen TD. Analysis of relative gene expression data using real-time quantitative PCR and the 2(T)(-Delta Delta C) method. Methods 2001; 25:402-408.

36. Minajigi A, Froberg J, Wei C, Sunwoo H, Kesner B, Colognori D, Lessing D, Payer B, Boukhali M, Haas W, Lee JT. A comprehensive Xist interactome reveals cohesin repulsion and an RNA-directed chromosome conformation. Science 2015; 349, doi: 10.1126/science.aab2276 aab2276.

37. Scheibe M, Arnoult N, Kappei D, Buchholz F, Decottignies A, Butter F, Mann M.. Quantitative interaction screen of telomeric repeatcontaining RNA reveals novel TERRA regulators. Genome Res 2013; 23: 2149-2157.

38. de Silanes IL, d'Alcontres MS, Blasco MA. TERRA transcripts are bound by a complex array of RNA-binding proteins. Nat Commun 2010; 1:1-9.

39. Negishi Y, Kawaji H, Minoda A, Usui K. Identification of chromatin marks at TERRA promoter and encoding region. Biochem Biophys Res Commun 2015; 467:1052-1057.

40. Thijssen PE, Tobi EW, Balog J, Schouten SG, Kremer D, El Bouazzaoui F, Henneman P, Putter H, Eline Slagboom P, Heijmans BT, van der Maarel SM. Chromatin remodeling of human subtelomeres and TERRA promoters upon cellular senescence. Epigenetics 2013; 8:512521.

41. Cusanelli E, Romero CAP, Chartrand P. Telomeric noncoding RNA terra is induced by telomere shortening to nucleate telomerase molecules at short telomeres. Mol Cell 2013; 51:780-791.

42. Dolci S, Levati L, Pellegrini M, Faraoni I, Graziani G, Di Carlo A, Geremia R.. Stem cell factor activates telomerase in mouse mitotic spermatogonia and in primordial germ cells. J Cell Sci 2002; 115:1643-1649.

43. Coussens M, Yamazaki Y, Moisyadi S, Suganuma R, Yanagimachi R, Allsopp R.. Regulation and effects of modulation of telomerase reverse transcriptase expression in primordial germ cells during development. Biol Reprod 2006; 75:785-791.

44. Pech MF, Garbuzov A, Hasegawa K, Sukhwani M, Zhang RJ, Benayoun BA, Brockman SA, Lin S, Brunet A, Orwig KE, Artandi, SE.. High telomerase is a hallmark of undifferentiated spermatogonia and is required for maintenance of male germline stem cells. Genes Dev 2015; 29:24202434.

45. Nergadze SG, Farnung BO, Wischnewski H, Khoriauli L, Vitelli V, Chawla R, Giulotto E, Azzalin CM. CpG-island promoters drive transcription of human telomeres. RNA 2009; 15:2186-2194.

46. Guibert S, Forne T, Weber M. Global profiling of DNA methylation erasure in mouse primordial germ cells. Genome Res 2012; 22:633641.

47. Smallwood SA, Kelsey G De novo DNA methylation: a germ cell perspective. Trends Genet 2012; 28:33-42.

48. Coussens M, Yamazaki Y, Moisyadi S, Suganuma R, Yanagimachi R, Allsopp R. Regulation and effects of modulation of telomerase reverse transcriptase expression in primordial germ cells during development. Biol Reprod 2006; 75:785-791.

49. Lee MW, Sadowska A, Bekere I, Ho D, Gully BS, Lu Y, Iyer KS, Trewhella J, Fox AH, Bond CS. The structure of human SFPQ reveals a coiled-coil mediated polymer essential for functional aggregation in gene regulation. Nucleic Acids Res 2015; 43:3826-3840.

50. Jaafar L, Li ZT, Li SY, Dynan WS. SFPQ center dot NONO and XLF function separately and together to promote DNA double-strand break repair via canonical nonhomologous end joining. Nucleic Acids Res 2017; 45:1848-1859. 